\title{
Sou professor Ejiwajegi/Kadiwéu
}

Gilberto Pires ${ }^{1}$

DOI: http://dx.doi.org/10.20435/tellus.v19i39.635

Preciso contar a minha história até chegar ao mestrado em Antropologia Social que faço junto ao Programa Pós-Graduação em Antropologia Social na Universidade Federal do Mato Grosso do Sul (UFMS). Para fazer isso achei que seria melhor dividir minha trajetória em fases: infância, juventude e vida adulta.

\section{DA INFÂNCIA}

No ano de 1966, no dia seis do mês de dezembro, aproximadamente ao meio dia nasci, sou o terceiro filho do casal Alfredo Pires e Inácia Bernardino, "criança nascida antes da hora", mas no momento certo para a minha família. Meus pais são Ejiwajegi (Kadiwéu) da Aldeia Libadi (Alves de Barros)². Cheguei como uma criança, segundo meus pais, que veio na boa hora por causa da recente perda de um filho de apenas três anos do jovem casal (meu pai com 26 anos e minha mãe 16 anos). Então o pequeno Gilberto Pires veio em boa hora.

Então, daí começou a minha a missão, além de nascer prematuro, mesmo assim trazia muita alegria para a família. Quando eu estava com dois anos de idade chega a Fundação Nacional do Índio (FUNAI) na Terra Indígena Kadiwéu, instalando-se no território do meu povo, na parte chamada de Nalique, uma antiga aldeia, que desta forma se torna a sede do órgão indigenista oficial do Estado brasileiro e, ao mesmo tempo, "institui" uma fazenda que tinha como objetivo ser o modelo agropecuário para a minha comunidade. A comunidade estava cheia de expectativas com o projeto novo na comunidade eu, Gilberto, aquela altura estava com cinco anos e ainda com "moleira aberta", mas, graças a chegada do Conselho Indigenista Missionário (CIMI), os religiosos logo diag-

1 Universidade Federal do Mato Grosso do Sul (UFMS), Campo Grande, Mato Grosso do Sul, Brasil.

2 Por razões étnicas escreverei primeiro na minha língua materna e depois colocarei entre parênteses os vocábulos em português para facilitar a leitura pelos não Ejiwajegi/Kadiwéu. 
nosticaram que estava com falta de cálcio e informaram que eu teria que tomar leite natural até fechar por completo a cabeça. Como existia a intervenção da FUNAI na pecuária, minha família conseguiu que the fosse emprestado cinco vacas leiteiras que o meu pai, Alfredo Pires, tirasse o leite todos os dias durante muito tempo da sua vida para nutrir as minhas necessidades e também as dos meus outros cinco irmãos.

Com oito anos de idade inicia-se um novo período em minha vida, começo a frequentar pela primeira vez a escola, graças a insistência da minha avó materna, dona Dorira, que eu acompanhava todos os dias, pois ela não queria ficar sozinha na escola por não saber falar uma palavra em português. A professora era a senhora Keila, esposa do missionário Geraldo da missão evangélica, instituição que havia chegado anos atrás em nossa aldeia.

Antes de ser alfabetizado chegaram as professoras gêmeas Ilka e Gilka, ainda, na época do coronelismo na década de setenta. E elas seguindo as regras da ditadura vigente no Brasil (1964-1985) começaram a alfabetizar na maneira rígida da qual ninguém escapava. Todos tinham que aprender a falar e a ler em língua portuguesa, processo de escolarização que me causou muito trauma pois, com frequência, ficava de castigo, por horas, ajoelhado nas pedrinhas, ou por horas intermináveis no pátio ao pé do coqueiro para que todos que passassem pudessem ver os castigados. Só quem passou por uma situação dessas sente o tamanho da humilhação, além das palmadas e puxões de orelhas que eram constantes no cotidiano escolar. Em suma, a escola para mim e para o meu povo começou como um ato de violência contra a nossa cultura e as nossas formas de educar as crianças.

Fora da escola eu tinha uma vida feliz, de uma criança normal, que brincava, sem esquecer as pequenas obrigações como: levar o almoço para o meu pai na roça; levantar de manhã para montar a égua preta e rodear o engenho de moer cana de açúcar para extração do walabo (garapa) que servia para fabricação de rapadura que era vendida na redondeza do meu território. Também, tinha horas de lazer para brincar com meus irmãos e primos, todas as vezes que nos juntávamos sempre fazíamos travessuras, brincadeiras de criança feliz! 


\section{DA JUVENTUDE}

Uma fase boa e também muito marcante, diz respeito aos anos oitenta quando a FUNAI criou alguns postos de vigilância nas imediações da divisa do nosso Território, período em que meu pai foi contratado para trabalhar como vigilante em um desses postos. Senti muita falta dele, pois se tornou um pai ausente, fiquei somente com a minha mãe, quando era jovem, na maior parte do tempo. Aproveitei esse tempo para me destacar e desenvolver talentos. Com treze anos me tornei um dos oficiais músicos da igreja local tocando violão.

$\mathrm{Na}$ escola tive boas notas, comecei a me interessar pela leitura e com quinze anos saí para trabalhar na fazenda Taquarusu, atualmente conhecida como Flôr da Bodoquena. Lá nessa fazenda, eu fazia de tudo, capinava e colhia café entre muitas outras atividades. O trabalho veio pelo desejo de me vestir com botas de cano longo que, à época, todos os garotos tinham, só eu que não.

Na volta dessa primeira experiência de trabalho fora do território do meu povo continuei estudando só que, à época, na aldeia, o ensino era oferecido apenas até a quarta série do fundamental, depois os alunos tinham que se deslocar para outro lugar se quisessem continuar com os estudos. Foi quando parei de estudar por falta de condições de ir viver na região do território do povo Terena, onde as escolas ofereciam a continuação do ensino fundamental.

Nesse período, como bom Ejiwajegi comecei a me apaixonar pela montaria em cavalo e me tornei peão por algum tempo. Na mesma época, me tornei um menino rebelde, nos conceitos do período, pois gostava de festas, encontros com amigos e muitas meninas, foi um período que na minha opinião foi uma fase de aprendizagem de vida.

Aos 18 anos me apaixonei por uma garota, e com 19 anos já estava amigado, aí o resultado é fácil de se imaginar, vieram os primeiros filhos. Sem saber direito o que fazer tive que me empenhar no trabalho de forma dobrada. Meu pai que foi contra o casamento, me deixou sem auxilio algum, e sozinho tendo que arcar com a criação dos filhos. Como sempre considerado pela comunidade como diferente, inteligente, capaz de aprender com facilidade as coisas e os ofícios, com o tempo, fui superando os desafios de ter a minha própria família.

No ano 1997 a professora que atuava na escola da aldeia, Dona Cleusa Alcântara, de etnia Terena e casada com um Ejiwajegi, entrou em licença de 
maternidade. Surgiu então a oportunidade de despertar um sonho que estava adormecido dentro de mim, de um dia voltar a estudar. De início fiquei seis meses de professor substituto e quando terminou o meu tempo, na despedida eu disse para os meus alunos, bastante emocionado, que um dia voltaria, mas, com a formação adequada de professor.

Em 1999 passei por uma experiência radicalmente diferente: sofri um atentado e levei um tiro a queima roupa na região da nuca e, só por milagre fiquei sem sequela nenhuma. Entretanto, gastei tudo o que tinha com médico particular e acabei ficando sem posses, pois o gado foi vendido, assim como a tropa de equinos e muares, tudo se foi. Até a esposa, mas ainda consegui perdoá-la, pois ela, ficou sem muita confiança em mim, afinal de contas quem me atirou em mim foi o irmão dela.

\section{COM ADULTO, VEIO A SUPERAÇÃO}

No ano de 2000 consegui entrar em um projeto de computação básica, no município de Bodoquena, onde estava morando. Aproveitei que estava na cidade e me matriculei na escola para continuar com meu sonho de terminar o curso em nível superior. Em 2001 abriu vagas para a primeira turma do magistério na aldeia, projeto no qual mergulhei de cabeça, pois vi que era minha oportunidade de continuar sonhando e realizando a vontade de estudar. Para completar esse caminho me contrataram no mesmo ano para lecionar para as séries iniciais. No final de 2004 concluí o magistério, porém, o partido político que criou o projeto do magistério perdeu a eleição e fiquei sem sala de aula, mas vi que era a minha oportunidade de partir para mais um desafio até então desconhecido por mim, a universidade.

No mesmo ano de 2005 prestei o primeiro vestibular na Universidade Estadual de Mato Grosso do Sul (UEMS), mas não consegui passar. No ano seguinte passei para cursar administração, porém acabei desistindo, por vários motivos: tempo, recursos e dificuldade com os estudos, entre outros. Fui morar na cidade de Bonito, onde foi implantado um núcleo da FUNAl e, em 2007, estava novamente estudando, dessa vez no curso de administração rural, no qual consegui me manter até o terceiro ano, mas acabei desistindo novamente por falta de condições financeiras. 
Nesse interim eu tinha passado no concurso da prefeitura de Bodoquena como secretário de escola, voltei à Bodoquena, fiquei apenas por um ano e resolvi voltar para a Terra Indígena, pois havia recebido uma excelente proposta do município de Porto Murtinho, para lecionar, com uma carga horária de 40 horas, em sala de aula. Novamente, por um curto período, pois fiquei por apenas seis meses no cargo. Nesse tempo, tinha concorri, em uma eleição, para a associação da comunidade, chamada Associação Indígena da Reserva Kadiwéu (ASIRK) a qual perdi, e acabei perseguido pela liderança que conquistou o posto eletivo. Tive que ir embora para Bonito novamente.

Em Bonito trabalhei por mais um semestre de vendedor externo de vários produtos de mercado, quando um belo dia tocou meu telefone, era a secretária de educação de Porto Murtinho, a qual, além de minha amiga, gostava muito do meu trabalho e, do telefonema resultou que fui enviado para Barro Preto, uma outra aldeia do mesmo Território Kadiwéu, onde trabalhei de 2010 a 2013 como professor regente.

Uma nova experiência conhecendo outra realidade de um povo quase isolado e que fica muito distante de qualquer cidade. A cidade, mais próxima, dista da aldeia aproximadamente de 150 km, era Bonito. Em 2011, passei no vestibular na UFMS, Licenciatura Intercultural Indígena com habilitação em Ciências Sociais, concluído em 2014, em seguida em 2015-2016 fiz especialização em Educação, História e Cultura Indígena pelo Centro Universitário Filadélfia (UNIFIL). Em 2017 consegui entrar no mestrado em Antropologia Social pela UFMS e agora estou aqui, escrevendo a minha dissertação para pensar a educação escolar indígena na Terra Indígena Kadiwéu e ao mesmo tempo refletir sobre a minha sociedade, na tentativa de me tornar um antropólogo, o primeiro do meu povo.

\section{Sobre o autor:}

Gilberto Pires - De pertença Ejiwajegi/Kadiwéu. Mestrando no Programa de Pós-Graduação em Antropologia Social na Universidade Federal do Mato Grosso do Sul (UFMS) e professor. E-mail: piresgilberto393@gmail.com

Recebido em 30 de novembro de 2018

Aprovado para publicação em 10 de maio de 2019 
